\title{
Changing Care Networks in the United Kingdom
}

\author{
London School of Economics Anthropology's COVID-19 and Care Research Group ${ }^{1}$
}

It is a truism to point out that the COVID-19 pandemic (and the United Kingdom government's response to it) has brought major disruption to everyday life. It has also, however, exposed and intensified existing fault-lines in society. The relationship between paid and unpaid labor, and the need to better recognize and reimburse the latter, long a key concern of feminist theorists and activists especially in relation to work within the household, has been one key issue of focus in our research. As parents with children have had to add childcare and home schooling to their work portfolios, there are reports of women in both middle-class and poorer households doing the lion's share. Meanwhile, as low-paid workers in the National Health Service (NHS), 'care' sector, and essential/key workers - often hailing from communities of recent or not-so-recent immigrants - have had to continue to work, other, higher-paid workers (not deemed to be 'key') have been able to stay safe by working at home; pre-existing inequalities between classes have been laid bare in ever-starker fashion. Pre-Covid, even after a decade of austerity, certain aspects of care for families in the lowpaid category were undertaken by a 'mixed economy' of welfare. ${ }^{2}$ This combined state welfare facilities, often provided at local level, with services rendered by charities staffed both by volunteers and salaried officers, while welfare payments known as 'universal credit' were delivered centrally by the Department of Welfare and Pensions. Now, in the time of coronavirus, these services have been thinned out, while lockdown has truncated informal sources of support in social relationships, making them difficult to draw on in times of need. This has caused anger and distress, and in some cases trauma. Whether people feel that the lockdown has been necessary or not, many of those in the low-paid sectors feel as though their situation - and suffering - is invisible to the government. Multiple forms of disadvantage emerge from this threat to the ties that bind people to each other.

\section{Background}

The COVID-19 pandemic, while having profound impacts on everyone in the United Kingdom regardless of race, class, gender, or region, has been and will be more severe for some communities than others. COVID-19 has brought inequalities of wealth and opportunity into sharp relief, rendering visible the social, economic, and political divisions at national, regional, and local levels - that prevent the formation of a more equitable society. Those who are losing out, in terms of both economic losses and health and mortality, are communities whose members have historically experienced poverty, inequality of opportunity, and discrimination over the past decades of austerity policy in the United Kingdom. They include, but are not limited to, members of black, Asian and minority ethnic groups (commonly glossed as BAME). However, many in these communities have accustomed themselves to doing without state support, and have formed robust mutual help and other forms of organization. Some have also come together to support each other in new

\footnotetext{
${ }^{1}$ LSE Department of Anthropology's COVID-19 and Care Research Group - Authors for purposes of citation: Laura Bear, Deborah James, Nikita Simpson, Eileen Alexander, Jaskiran K. Bhogal, Rebecca E. Bowers, Fenella Cannell, Anishka Gheewala Lohiya, Insa Koch, Megan Laws, Johannes F. Lenhard, Nicholas J. Long, Alice Pearson, Farhan Samanani, Milena Wuerth, Olivia Vicol, Jordan Vieira, Connor Watt, Catherine Whittle, Teodor Zidaru-Barbulescu

${ }^{2}$ Hugh Cunningham and Joanna Innes, eds., Charity, Philanthropy and Reform, from the 1690s to 1850 (London, MacMillan, 1998).
} 
and improvised ways as a result of the crisis, but in ways that lockdown has rendered unstable and precarious.

The research undertaken by LSE Anthropology's Covid and Care Research Group, through online and telephonic interviews with community leaders (including faith leaders, trade union representatives, and advisers), community groups, and individuals in four broad sites (London, the Midlands, the North East, and Scotland), sought to identify the effects of these new forms of disadvantage on caring processes within and beyond the household. We aimed to explore, among other things, how government policies aimed at responding to the pandemic are generating new forms of inequality (intensified social divides, stigma, social isolation, and discrimination), and how pre-existing and new care networks are responding to these in order to sustain life (through caring labor, financial aid, social support, and the like). Such networks of care - which cross-cut categories of class, ethnicity, and region comprise formal interactions with the state, third sector, and civil society organizations as well as informal interactions with kin, friends, neighborhoods, and communities.

Our research was animated by a feminist substantivist approach ${ }^{3}$ together with an interest in the increasing importance of care, ${ }^{4}$ economies of advice, ${ }^{5}$ and the third sector. ${ }^{6}$ It pays attention to how care in society is configured, and how unpaid, informal care networks of households, families, and communities sustain productive, economic life, often in complex interaction with the vestigial remnants of older state-driven welfare schemes, access to which requires the expenditure or effort, empathy, and care. This approach challenges the division between the domestic and public spheres of society, and the boundedness of the economic domain. ${ }^{7}$ In bringing our findings to the attention of policy-makers at national and local levels, we have sought to make it clear how the local solutions being generated by communities - in interaction with other actors - might, and should be, amplified, thus building on solutions already in place rather than inventing new ones.

\section{Policy and the domestic arena}

We start with the arena - much-contested by feminists for half a century - of the household. The succession of new social distancing guidelines and economic policies implemented by the government were modelled on two assumptions. First, heteronormative and middle-class conceptions of the nuclear family have led to unintended consequences, such as the exclusion

\footnotetext{
${ }^{3}$ Laura Bear, Karen Ho, Anna Lowenhaupt Tsing, and Sylvia Yanagisako, "Gens: A Feminist Manifesto for the Study of Capitalism," Cultural Anthropology, March 30, 2015, https://culanth.org/fieldsights/gens-a-feministmanifesto-for-the-study-ofcapitalism\#: : :text=\%20Gens $\% 3 \mathrm{~A} \% 20 \mathrm{~A} \% 20$ Feminist $\% 20$ Manifesto $\% 20$ for $\% 20$ the $\% 20$ Study,of $\% 20$ Gender $\% 2$ C\%20Race $\% 2 C \% 20$ Sexuality\%2C\%20and\%20Kinship\%0AA...\%20More\%20, accessed 8/9/2020; Nancy Fraser, "Can society be commodities all the way down? Post-Polanyian reflections on capitalist crisis," Economy and Society 43:4 (2014): 541.

4 Ana P. Gutiérrez Garza, Care for Sale: An Ethnography of Latin American Domestic and Sex Workers in London (Oxford: Oxford University Press, 2018); Victoria Lawson, "Geographies of Care and Responsibility 2007," Annals of the Association of American Geographers 97 (2007): 1-11.

5 Insa Koch and Deborah James, "The State of the Welfare State: Advice, Governance and Care in Settings of Austerity," Ethnos, February 24, 2020, https://www.tandfonline.com/doi/full/10.1080/00141844.2019.1688371, accessed 8/9/2020; Deborah James and Insa Koch, "Economies of advice," in Mark Aldenderfer, ed., Oxford Research Encyclopedias: Anthropology (Oxford: Oxford University Press, 2020).

${ }^{6}$ Catherine Alexander, "Third Sector," in Keith Hart, Jean-Louis Laville, and Antonio David Cattani, eds., The Human Economy, a citizens' guide (Cambridge: Polity Press, 2010).

${ }^{7}$ Diane Coyle, Markets, State, and People: Economics for Public Policy (Princeton: Princeton University Press, 2020).
} 
and/or stigmatization of single-parent households, multigenerational households without access to online resources, and single men. Second, the assumption that the 'economy' operates - independently of households - according to the rules of the free market, and is 'disembedded' from social and moral life, has resulted in a push to 're-open the economy' and allow people to return to paid work before allowing them to engage in unpaid caring work between households. As one member of our team observed, it is as though 'money disinfects.' Conversely, relationships based on care, neighborhood, and kinship are treated as though they are contagious, even indicative of danger.

To elaborate: the role of unpaid caring labor in sustaining economic and social life has been side-lined even more than it is under normal circumstances. Traditional gender roles have been reinforced by policies that do not account for such informal care. Households have had to absorb care for elderly, children, the disabled, and those with special needs, without the support of public institutions such as schools, community centers, and social support services. The inability of households, under lockdown, to access informal networks of care through kin, friends, and neighbors has forced many to fill the gap by using paid care, and left others unable to meet their needs. Meanwhile, these needs are intensifying as the return of increasing numbers of citizens to the workplace heightens the care deficit in households during working hours. The choice to prioritize re-opening of the 'economy' has produced newly intensifying inequalities between households who, in order to return to work, are able to pay to replace their caring labor at home, in the form of nannies, care workers, or cleaners, and those who cannot. This latter group risks loss of income, indebtedness, and loss of employment.

The ideological and discursive divide between the domain of the household and the public domain has thus become more visible and salient in the public imagination. As a result, the work of the household in sustaining economic life is further obscured. When certain groups such as single parents and mothers in nuclear households unable to pay for care - are then prevented from returning to the workforce, they face financial difficulty and mental distress. (The lack of support from kin and formal care networks has been particularly difficult for new mothers). Parents have been reluctant to take their children to the hospital, or unable to access support from formal support services such as general practice clinics, nurseries, and community centers.

In addition to their struggles to gain or retain access to formal and informal networks of care, previously (and now newly) disadvantaged households have experienced difficulties in accessing vital necessities including schools, the internet and IT resources, and food. Significant effects - on mental health and wellbeing, education, income, nutrition, and domestic violence levels - have been widely documented. Schools previously provided key services to families, ranging from referral to social workers, domestic violence services, and special needs support, but such provision has been discontinued with their closure. Greater responsibility has been placed on parents to attend to the educational and emotional needs of their children while they are unable to go to school or nursery; a burden that has largely fallen on mothers, including those with poor literacy or IT skills. The division of roles along gender lines, in households that previously had two working parents, has intensified, which has affected the way employers see their female employees. Partners of key workers, or of employees who are now returning to work as lockdown eases, face particularly heavy care burdens during working hours. 
Single parents, most often single mothers, have faced particularly severe challenges in reconciling the demands of work with those of the family. They have often been forced to choose between paid employment and childcare, foregoing income or compromising the needs of their children. In one case a single mother who, was already in a precarious situation in good times, was forced to stay at home with her children, unable to leave them even to go shopping. She was likely to lose her job. Many report being forced to make similarly complex calculations of risk in attending to the needs of their children, balancing risk of exposure to COVID-19 with the need to access food banks, medical help, and social care services for themselves or their children. There have been reported rises in calls and referrals to childcare support services by single-parent families, particularly single mothers and pregnant women who are refugees or asylum seekers. With extended family networks truncated, single parents are unable to access respite care or informal sources of food provision for their children. Respondents to a survey reported feeling increasingly distant from non-relatives, including friends, colleagues, and partners living outside the home. The breakdown of child maintenance payments means some partners are not required to pay child support, leaving one parent without an income. Nor does state welfare provision necessarily ameliorate the problem. The lag in universal credit and other benefit payments has had a particularly egregious effect on single-parent households.

In the case of multigenerational households, especially those stretched for resources, the lockdown has resulted in a 'squeezed middle' - with middle-aged women providing physical and financial support to both their elderly relatives and children. Multigenerational households, especially in BAME communities where such living arrangements are more common, and particularly in deprived communities where there is overcrowding of spaces, have tended to be stigmatized as vectors of transmission. In the case of households where dependence is more common, such as those containing elderly or disabled members, the lockdown has truncated networks of personal care. This means that many people providing such care (most often women) have become isolated, unable to access respite care. In the case of single-person (male) households, individuals experiencing financial stress have been likewise isolated from sources of emotional, financial, and physical care, whether this be because they are ashamed of asking for support or remote from networks that might provide it.

To contextualize these in-the-household effects, we move on to sketch some of the broader parameters, focusing especially on the changes to state welfare provision noted earlier.

\section{Care Provision}

Under lockdown, state interactions with vulnerable people, and the third sector activities which during the austerity era had already begun to replace these,${ }^{8}$ have been stripped back. Besides central areas of concern, such as food provision, help for domestic violence, child protection, and mental health, other activities that usually mediate, cushion, or replace caring interactions with the state have dwindled. In parallel, those formerly relying on such systems have experienced a sense of stigma about accessing services that render visible their experience of poverty, violence, or deprivation. For example, distanced queues for social welfare or food banks make people visible, and a visit from a social worker is more carefully observed by neighbors. The sense of stigma is particularly acute for men, especially from migrant communities, for whom the role of breadwinner and the value of work is important

\footnotetext{
${ }^{8}$ Insa Koch and Deborah James, "The State of the Welfare State".
} 
to a sense of self-worth. Hence, even where care has not been stripped back, the idea of being a recipient of welfare or charity is perceived as degrading and shameful.

Parents have experienced intensified disadvantage as a result of the closure of public spaces such as schools, libraries, and children's centers, which formerly provided referral, advice about, or mediated access to social services as well as face-to-face support to parents (including free school meals). Schools, engaging in a process of trial and error to keep the children of poorer families fed in lockdown, with some inviting families to collect food from school, then decided that this contradicted 'stay at home' guidelines. Shielding families were left under-served. The move to food vouchers was welcomed since this empowered families to choose their own food for their children but parents reported that it was often difficult to use them; vouchers have been impossible to cash in, recipients face long wait times on welfare websites, or have difficulty in securing slots for delivery of groceries from allocated stores. The closure of public spaces has also affected referral systems for individuals experiencing domestic abuse. Many are unable to access public spaces such as schools or libraries, women's groups, or the technology that is needed to reach out for help or to be contacted by professionals. Some schools and other social services have tried to compensate for not seeing service users or students by making phone calls or home visits, or asking to see the pupil when delivering food, to maintain welfare monitoring. While those about whom there were existing welfare concerns or known vulnerabilities have been contacted by service providers, problems have gone unnoticed for those developing new mental health problems or experiencing new social or relational problems in the household during lockdown.

As schooling has gone online, strengths and weaknesses have been exposed. The latter have come to the fore, in particular, because of the digital inclusion gap. Children in economically disadvantaged households have poorer access to technology and the internet, and schools worry about the challenges of later 'closing the gap' between advantaged and disadvantaged scholars after lockdown. Supporting education at home has been more difficult for parents with poor literacy or IT skills, or those who are learning English. Parents living in temporary housing or other overcrowded spaces, particularly women who have left abusive households, are likewise finding it difficult to support their children in education.

Institutional care interventions are a site of increasing distress. More children are being taken into care, and, during lockdown, have been forbidden from having regular face-to-face contact with their parents while their case is under consideration: a situation particularly acute for women who have recently given birth. Falling into the economically disadvantaged bracket, most parents in this situation lack access to digital platforms to interact with their children via technology, where this might otherwise have been arranged.

These developments, reaching back to before the lockdown, need to be seen from a long-term perspective. For ten years prior to lockdown, the government's austerity policies saw care provision at local level thinned out. ${ }^{9}$ It is certainly true that local, community-based initiatives came into being to substitute for these, particularly among those seeking to evade state gaze. As noted in the next section, for example, new collaborations between the local state and the third sector have filled the gap left when state provision and funding was withdrawn. Nevertheless, disparities in funding allocated to these authorities have exacerbated inequalities between boroughs, with wealthy ones more able to support the ecosystem of service provision than their more deprived counterparts. The latter are often

\footnotetext{
${ }^{9}$ Deborah James and Insa Koch, "Economies of advice”.
} 
those that have experienced higher COVID-19 caseloads and excess deaths. Small grants given out by local authorities were important and well-received, but limited and often insufficiently targeted to meet the needs of communities. Many local charities and social enterprises, such as in the case outlined below, were unable to access the Coronavirus Small Business Loan Scheme, as their 'rateable value' ${ }^{10}$ was above the threshold. Grassroots services are often funded voluntarily by their communities and unable to access local authority grants, which has threatened their long-term sustainability. Social workers and other support staff are not permitted under statutory regulations to refer people to such services, despite the fact that they often meet the needs of vulnerable service users better than formal services do. Meanwhile, paid-for care is beyond their means. There is thus a risk that local authorities become dependent on informal care providers to meet the service gap, without adequately compensating them.

With this patchy set of provisions, it is perhaps hardly surprising that families in minority communities, already suspicious of state welfare arrangements, social workers, and the like and now even less likely to be benefitting from whatever such officers normally supply have come increasingly to mistrust state bodies. Especially those with the in-between status that forbids them access to public funds ('No recourse to public funds'; NRPF), ${ }^{11}$ and refugees who are in the process of being resettled and unsuccessful asylum seekers, report that they are stuck in limbo, fearful that accessing charitable or local authority services will make them visible to the state. In addition, engagement with government information and guidelines is informed by existing relationships of trust and mistrust, with a lack of clear messaging from government sources meaning that people have little understanding of social distancing guidelines and government policy changes. It is under these circumstances that many, already involved in neighborhood and community systems of care, have intensified that involvement.

\section{State or community? A 'mixed economy of welfare'}

Grassroots community support services, often informal, cultural, or faith-based and local, have been of critical importance in supporting isolated families, providing culturally-specific information, and advice in navigating welfare, health, and financial support. Particularly those marginal communities with poor English and IT literacy, who do not engage with mainstream media outlets and who thus receive information on epidemiology in a mediated way, have come to rely on these interpersonal interactions with community networks, gatekeepers, or trusted advisors. Such local responses, however, are not routinely as simple and binary as the above account may suggest. The cards do not always fall in a manner as simple or predictable as pro- or anti-state; pro- or anti-community. To illustrate the complex interaction of factors that mean a 'mixed economy of welfare' 12 remains a prominent pattern in the United Kingdom, we highlight two cases in particular.

The first is from Leicester, the site of the United Kingdom's first localized lockdown and which became notorious for the working conditions in its garment factories. Here, the Highfields Community Centre, for forty years serving one of the most deprived areas in the city with a predominance of BAME groups, continued to give support to local residents and

\footnotetext{
${ }^{10}$ Basis for calculating business rates.

${ }^{11}$ This status is imposed on certain categories of people for whom the permission to remain in the United Kingdom is contingent on being prohibited from accessing certain defined public funds, especially welfare benefits.

${ }^{12}$ Hugh Cunningham and Joanna Innes, eds., Charity, Philanthropy and Reform, from the 1690s to 1850.
} 
newly-arrived asylum seekers alike. The decade of austerity, during which the local authority (starved of support by central government) cut funding by half a million pounds, forced the center to rely instead on grants from bodies such as Children in Need and the Lottery Fund (the increasing prevalence of this kind of 'patchwork funding' ${ }^{13}$ has been a common pattern around the country during the austerity decade). Since the lockdown in March, the center has been closed. In a demonstration of the poorly-thought-through character of central government provision with its conditionalities, they were unable to access the government business support as their value was calculated as being above the rateable value. Nonetheless, the center kept going; it soon started a food parcel delivery service and has seen the demand double. This service enabled staff to keep in touch with vulnerable users, including young people, elderly, and the unemployed who belong to a local 'jobs club.' Accessing a small grant, they also sent out community workers wearing personal protective equipment to persuade parents who are reluctant to send their children back to school or nursery, reasoning that failure to do so would lead to further disadvantage in the longer term. In addition, they are considering seeking funds for summer schools using creative methods to help children catch up for lost time in education and lack of psychosocial support.

The second case is from Kensington and Chelsea, the borough that in 2017 saw the disastrous Grenfell fire destroy a high-rise council building and kill seventy-two people. Here, the building of community networks in response to that incident proved resilient in helping to provide protection and care in the face of the pandemic. The mismatch between government policy and the advice of the World Health Organization and health specialists in countries already responding to the virus encouraged some local charity leaders to begin joint preparations for the effects of a likely lockdown. In part as a result of the fire, there was already a spirit of community cooperation across faiths and across denominations within faiths. Showing that not all government officers were mistrusted, "local charities were assisted by a trusted NHS worker at their first meeting, at which he noted the difference between his advice as an official, and his advice as a citizen." The organizers reached out to "trusted statutory leaders in both the local authority and health authority" - including officers from Public Health England and from West London Clinical Commissioning Group as well as representatives from key charities and the voluntary sector - on the basis of their "integrity, honesty, and diligence." The pandemic response was thus "based around a multisectoral group that trusted each other from the start and were open to challenging 'business as usual ". ${ }^{14}$ One of those involved was the CEO of the Al Manaar Muslim Cultural Heritage Centre, which was already offering multilingual telephone advice (in Arabic, English, Berber, French, and Turkish). To help elderly people who were housebound because of vulnerability or infection, they teamed up with various charities. In addition, realizing that the mosque closed for prayers during lockdown - was an important asset/resource, they started using it as a distribution hub for food distribution.

\section{Conclusion}

The two cases detailed here demonstrate the salience of observations about the importance of third sector and/or locally generated initiatives in the face of state withdrawal and statedriven austerity. Both to offset these longer-term processes and to help cope with the belated,

\footnotetext{
13 Alice Forbess and Deborah James, "Innovation and Patchwork Partnerships: Advice Services in Austere Times," Oñati Socio-Legal Series 7:7 (2017), http://ssrn.com/abstract=3056205, accessed 8/09/2020

14 Michael Ashe, Testimony to Parliament, 2018, https://committees.parliament.uk/writtenevidence/8142/pdf/, accessed 8/09/2020.
} 
patchy, and often inadequately communicated measures taken by the United Kingdom government to counter and control the spread of the COVID-19 pandemic, activities that are informal - and often voluntary and unpaid - intensify to fill in for the thinning of state services, as is the case with other "economies of advice." ${ }^{15}$ Care, in turn, entails "the construction of new forms of relationships, institutions, and action," which may (but do not always) "enhance mutuality and well-being." 16 Paid and unpaid work, market and nonmarket, formal and informal, neoliberal and redistributive here coexist in a tight embrace.

${ }^{15}$ Deborah James and Insa Koch, "Economies of advice".

${ }^{16}$ Victoria Lawson, "Geographies of Care and Responsibility 2007”. 